\title{
A orbifloxacina no tratamento das cistites bacterianas em gatos domésticos
}

\author{
The orbifloxacin in the treatment of lower urinary tract infections in cats
}

\author{
Archivaldo Reche Junior ${ }^{1}$
}

\section{RESUMO}

O presente estudo teve como objetivos, avaliar o uso da orbifloxacina nas cistites bacterianas de felinos, e seus possíveis efeitos colaterais, mormente a nefro e/ou hepatotoxicidade. Para tanto, foram colhidas amostras de urina de 53 gatos com históricos variados, mas com predisposição à infecção urinária. A cistite bacteriana foi comprovada, através de exame microbiológico, em 13 pacientes. No entanto, apenas 10 apresentaram infecção por agentes sensíveis a orbifloxacina. Esses 10 pacientes foram então submetidos ao tratamento com orbifloxacina na dose de $2,5 \mathrm{mg} \mathrm{kg}^{-1}$ a cada 24 horas por 10 dias. Não houve crescimento bacteriano nas amostras de urina submetidas à cultura, 72 horas após a interrupção do tratamento. Não foram observados sinais de nefro e/ou hepatotoxicidade nesses pacientes, uma vez que os níveis séricos de alanina aminotransferase (ALT), aspartato aminotransferase (AST), fosfatase alcalina (FA), albumina, uréia e creatinina não tiveram variação significativa após o uso do fármaco. Portanto, os resultados apresentados sugerem que a orbifloxacina pode ser usada como agente antimicrobiano nas infecções urinárias de felinos.

Palavras-chave: gatos, orbifloxacina, infecção do trato urinário inferior.

\section{ABSTRACT}

The main goals of this study were the evaluation of orbifloxacin in the treatment of lower urinary tract infection in cats, and its toxicity mainly to kidney and/or liver. To achieve these goals, quantitative urine cultures were performed in 53 urine samples, collected from cats with signs of lower urinary tract infection. Bacterial cystitis was confirmed in 13 cats, however in only 10 samples the isolated bacteria was in vitro susceptible to orbifloxacin. These 10 cats with bacterial cystitis were submitted to the treatment with orbifloxacin $\left(2.5 \mathrm{mg} \mathrm{kg}^{-1}\right.$ once a day/10 days). Seventy two hours after finishing the treatment, urine samples were collected and cultured again. The results were a negative urine culture for all ten cats. No signs of liver and/or kidney toxicity were observed in these cats since the serum liver enzymes alanine aminotranferase (ALT), aspartate aminotransferase (AST), alkaline phosphatase (AP) and serum albumin, besides urea and creatinine have not changed after using this drug. These results suggest that orbifloxacin can be safely used as an antibacterial drug for urinary tract infection in cats.

Key words: cats, orbifloxacin, lower urinary tract infection.

\section{INTRODUÇÃO}

A infecção urinária bacteriana em cães corresponde a uma das mais freqüentes afecções causadoras de sinais como hematúria, disúria e polaciúria. Em contraste, os resultados de diferentes ensaios clínicos e laboratoriais indicam que os felinos são resistentes às infecções bacterianas das vias urinárias (SCHECHTER, 1970; BARSANTI et. al., 1982; LEES et al., 1984; KRUGER et al., 1991).

Em estudo prospectivo de gatos com doenças do trato urinário inferior, RECHE JUNIOR et al. (1998) observaram que apenas 8\% deles apresentaram crescimento bacteriano na cultura de urina, onde os agentes isolados foram: Pasteurella spp, Klebsiella spp, Staphylococcus spp e Escherichia coli. No entanto, todos esses animais haviam sido submetidos à sondagem uretral prévia para desobstrução uretral, o que fatalmente poderia ter propiciado a instalação e proliferação dos agentes infecciosos.

${ }^{1}$ Departamento de Clínica Médica da Faculdade de Medicina Veterinária e Zootecnia da Universidade de São Paulo (FMVZ-USP), Av. Prof. Dr. Orlando Marques de Paiva, 87, Cidade Universitária, 05508-000, São Paulo, Brasil. E-mail: valdorec@usp.br 
A baixa freqüência da infecção urinária bacteriana em gatos pode estar relacionada a mecanismos locais de defesa, altamente efetivos, dentre os quais destacam-se a capacidade dos felinos em produzir uma urina altamente concentrada, podendo a densidade urinária chegar a valores superiores a 1,080. O consumo de dietas ricas em proteínas, proporciona a formação de urina naturalmente ácida e altamente concentrada em uréia (LEES et al., 1979; OSBORNE et al., 1979; OSBORNE et al., 1989). Portanto, pode-se pressupor que a perda de um ou mais desses mecanismos de defesa possam predispor o gato às cistites bacterianas.

Em um estudo retrospectivo realizado por DAVIDSON et al. (1992), demostrou-se que o cultivo de 1380 amostras de urina de felinos evidenciou-se crescimento bacteriano em $25 \%$ delas. Ainda, a idade média dos felinos que apresentavam infecção bacteriana urinária era de 10,6 anos. Esses fatos sugerem que tal afecção deva ser um problema potencialmente importante em gatos idosos. Possivelmente, uma alteração nas defesas do trato urinário contra agentes infecciosos faz com que os gatos mais velhos sejam mais susceptíveis a infecção urinária, no entanto não se sabe se essa seria apenas uma conseqüência do processo de envelhecimento ou uma condição secundária às doenças que são mais comuns em gatos idosos (insuficiência renal crônica, Diabetes mellitus, hipertireoidismo).

Considerando-se que as bactérias mais comumente isolados na urina de felinos com cistite são: Escherichia coli, Staphylococcus spp, Streptococcus spp, Proteus spp, Klebsiella spp e Pseudomonas spp, e que os antimicrobianos do grupo das fluoroquinolonas podem ter ação in vitro e in vivo contra esses agentes, tem-se preconizado mormente a enrofloxacina na terapia desses pacientes (LEES \& ROGERS, 1986). A orbifloxacina é outro fármaco pertencente a esse grupo e que tem indicação para tratamento das infecções de pele e tecidos moles de cães e gatos e infecções do trato urinário em cães. Em gatos existem poucos relatos referentes a sua utilização nas infecções urinárias.

As fluoroquinolonas têm atividade contra microrganismos gram negativos, inibindo a subunidade A da girase do DNA bacteriano, e gram positivos, inibindo a topoisomerase tipo IV do DNA bacteriano, culminando, em ambos os casos com a fragmentação dessa molécula e conseqüente desarranjo celular (ÁRKÖZY, 2001).

A excreção das fluoroquinolonas é principalmente renal. Portanto deve ser usada com bastante cautela em pacientes que apresentem diminuição na capacidade de excreção renal (ÁRKÖZY, 2001).

Este trabalho teve como objetivos, avaliar a aplicabilidade da orbifloxacina no tratamento das infecções urinárias de gatos domésticos, e as possíveis ações nefro e hepatotóxicos da orbifloxacina, na dose preconizada pelo fabricante: $2,5 \mathrm{mg} \mathrm{kg}^{-1}$ a cada $24 \mathrm{~h}$ por10 dias, através das dosagens séricas de uréia, creatinina, alanina aminotransferase (ALT), aspartato aminotransferase (AST), fosfatase alcalina (FA) e albumina.

\section{MATERIAL E MÉTODOS}

Foram colhidas amostras de urina de 53 felinos que estavam em acompanhamento clínico no HOVET-USP ou em uma clínica veterinária particular (VETMASTERS) e que tinham indicação para a realização de exame microbiológico da urina tais como, pacientes com insuficiência renal crônica (IRC), Diabetes mellitus (DM), obstrução uretral, doença do trato urinário inferior dos felinos (DTUIF), hipertireodismo e gatos com uretrostomia perineal.

Para a análise microbiológica da urina, o material coletado foi semeado em placas com cultivo de aeróbios (meio ágar sangue e Mac Conkey) e incubados a $35 \pm 1^{\circ} \mathrm{C}$ por 24 a 48 horas.

Após o tempo de incubação, as placas foram examinadas observando-se o crescimento das colônias. Em seguida, realizou-se a coloração de Gram para isolamento das colônias Gram positivas e Gram negativas. Após a identificação e quantificação dos agentes microbiológicos isolados, foi realizado o antibiograma, avaliando-se a sensibilidade do agente isolado a orbifloxacina e a outros antimicrobianos testados rotineiramente no referido laboratório.

Os animais com infecção bacteriana das vias urinárias, cujo agente isolado foi sensível à orbifloxacina, foram submetidos ao tratamento antimicrobiano, utilizando-se o ORBAX ${ }^{\circledR}$ (orbifloxacina), na dose de $2,5 \mathrm{mg} \mathrm{kg}^{-1}$ a cada 24 horas, via oral, por um período total de 10 dias.

Os efeitos nefro e/ou hepatotóxicos nos gatos submetidos ao tratamento foram avaliados, indiretamente através das dosagens séricas de uréia, creatinina, alanina amonotransferase (ALT), aspartato aminotransferase (AST), fosfatase alcalina (FA) e albumina, 24 horas antes e 72 horas após a conclusão do tratamento. As análises bioquímicas foram feitas em analisador automático (Liasys Roche), utilizandose, quando necessário, "kits” comerciais. Para as dosagens séricas de uréia empregou-se o método enzimático da uréase/GLDH, em ultra-violeta - Bayer 
(T 01-1821-56). As dosagens de creatinina foram realizadas pelo método colorimétrico de Jaffé modificado. As dosagens de alanina aminotransferase e aspartato aminotransferase foram realizadas pelo método cinético ultra-violeta (Boehringer-Mannheim 1087576 e 1087550, respectivamente). A fosfatase alcalina sérica foi mensurada pelo método cinético colorimétrico - Bayer (6391) e a albumina pelo método colorimétrico do verde de Bromocresol.

A eficácia do tratamento pôde ser comprovada com a realização de nova cultura de urina 72 horas após a interrupção do tratamento.

Deve-se ressaltar que esses animais não receberam nenhum outro fármaco, além da orbifloxacina, durante o período experimental.

Todas as determinações estatísticas foram realizadas com o auxílio do "software" SAS - Statistical Analysis System v.8.1. Foram calculadas as médias e desvios padrões dos valores de uréia, creatinina, ALT, AST, FA e albumina antes e após o tratamento. As variações desses valores foram analisadas pelo teste $t$ student, utilizando-se como nível de significância 5\% ( $\mathrm{P}<0,05)$, conforme recomendado por VIEIRA (1991).

\section{RESULTADOS}

Na primeira fase do experimento, foram colhidas amostras de urina de 53 gatos com histórico que pudesse sugerir infecção do trato urinário inferior. Considerou-se infecção do trato urinário quando o número de bactérias isoladas da urina fosse superior a
100.000 $\mathrm{ml}^{-1}$. Das 53 amostras de urina testadas, comprovou-se o crescimento bacteriano em apenas $24,5 \%(n=13)$, com isolamento de 15 agentes bacterianos, ou seja em 15,4\% $(n=2)$ das amostras obteve-se o isolamento de mais de um agente bacteriano (Tabela 1).

Dentre os 15 agentes bacterianos isolados, $80 \%(n=12)$ mostraram-se sensíveis à orbifloxacina in vitro. Dos animais de números 29 e 46, foram isoladas duas bactérias de gêneros diferentes, sendo ambas sensíveis à orbifloxacina (Tabela 1). Portanto, apenas 10 dos 13 gatos com cistite bacteriana puderam ser utilizados na segunda fase desse estudo, onde se avaliou a eficácia in vivo da orbifloxacina frente aos agentes isolados (Tabela 2). A insuficiência renal crônica foi à condição mórbida mais freqüente entre os gatos com cistite bacteriana, correspondendo a $46 \%$ $(n=06)$ do total. A obstrução uretral 15,5\% ( $n=02)$, uretrostomia perineal $15,5 \%(n=02)$, doença do trato urinário inferior dos felinos $15,5 \%(\mathrm{n}=02)$ e a Diabetes mellitus 7,5\% $(n=01)$, foram outras condições associadas à cistite bacteriana nos gatos do presente estudo.

Os valores laboratoriais testados na avaliação de possíveis efeitos nefro e/ou hepatotóxicos, antes e após o tratamento com a orbifloxacina, encontram-se dispostos no Tabela 2. Não houve variação significativa em nenhum dos parâmetros ao término do tratamento $(\mathrm{P}>0,05)$.

Cerca de 72 horas após o término do tratamento, repetiu-se a cultura de urina de todos os

Tabela 1 - Resultado do exame microbiológico da urina dos 13 gatos com suspeita de cistite bacteriana, segundo histórico clínico e a sensibilidade do agente isolado à orbifloxacina. São Paulo, 2004.

\begin{tabular}{|c|c|c|c|}
\hline Número & Histórico & $\begin{array}{l}\text { Resultado/Agente isolado } \\
\qquad(+100.000 \mathrm{UFC} / \mathrm{ml})\end{array}$ & $\begin{array}{l}\text { Sensibilidade do agente à } \\
\text { orbifloxacina (in vitro) }\end{array}$ \\
\hline 01 & Insuficiência renal crônica & Escherichia coli & sensível \\
\hline 04 & Uretrostomia & Corynebacterium spp & resistente \\
\hline 06 & $\begin{array}{l}\text { Doença do trato urinário inferior dos } \\
\text { felinos }\end{array}$ & Escherichia coli & sensível \\
\hline 10 & Diabetes Mellitus & Klebsiella spp & resistente \\
\hline 12 & Insuficiência renal crônica & Escherichia coli & sensível \\
\hline 13 & $\begin{array}{l}\text { Doença do trato urinário inferior dos } \\
\text { felinos }\end{array}$ & Enterobacterium spp & sensível \\
\hline 23 & uretrostomia & Staphylococcus spp & sensível \\
\hline 26 & Insuficiência renal crônica & Klebsiella spp & sensível \\
\hline 29 & Obstrução uretral & $\begin{array}{l}\text { Escherichia coli } \\
\text { Streptococcus spp }\end{array}$ & $\begin{array}{l}\text { sensível } \\
\text { sensível }\end{array}$ \\
\hline 33 & Insuficiência renal crônica & Proteus spp & sensível \\
\hline 38 & Insuficiência renal crônica & Escherichia coli & resistente \\
\hline 43 & Insuficiência renal crônica & Streptococcus spp & sensível \\
\hline 46 & Obstrução uretral & $\begin{array}{l}\text { Staphylococcus spp } \\
\text { Escherichia coli }\end{array}$ & $\begin{array}{l}\text { sensível } \\
\text { sensível }\end{array}$ \\
\hline
\end{tabular}

Ciência Rural, v.35, n.6, nov-dez, 2005. 
Tabela 2 - Resultados das dosagens séricas de Alanina aminotransferase (ALT-UL ${ }^{-1}$ ), Aspartato aminotransferase (AST-UL ${ }^{-1}$ ), Fosfatase alcalina (FA-UL $\left.{ }^{-1}\right)$, albumina $\left(\mathrm{Ab}-\mathrm{gdL}^{-1}\right)$, uréia $\left(\mathrm{Ur}-\mathrm{mgdL}^{-1}\right)$ e creatinina $\left(\mathrm{Cr}-\mathrm{mgdL}^{-1}\right)$, dos 10 felinos submetidos ao tratamento com orbifloxacina, 24 horas antes do início do tratamento e 72 horas após o término do tratamento. São Paulo, 2004.

\begin{tabular}{|c|c|c|c|c|c|c|c|c|c|c|c|c|}
\hline \multirow{2}{*}{ Número } & \multicolumn{6}{|c|}{ Dosagens séricas antes do tratamento } & \multicolumn{6}{|c|}{ Dosagens séricas após o tratamento } \\
\hline & $\mathrm{ALT}$ & AST & FA & $\mathrm{Ab}$ & Ur & $\mathrm{Cr}$ & ALT & AST & FA & $\mathrm{Ab}$ & $\mathrm{Ur}$ & $\mathrm{Cr}$ \\
\hline 01 & 35 & 22 & 78 & 2,5 & 120 & 3,5 & 42 & 19 & 89 & 2,4 & 112 & 3,7 \\
\hline 06 & 50 & 18 & 65 & 2,7 & 85 & 3,0 & 45 & 27 & 75 & 2,3 & 58 & 2,5 \\
\hline 12 & 25 & 12 & 15 & 2,9 & 75 & 2,9 & 30 & 33 & 38 & 2,0 & 80 & 3,2 \\
\hline 13 & 37 & 45 & 57 & 2,5 & 100 & 4,0 & 55 & 45 & 100 & 2,8 & 130 & 4,5 \\
\hline 23 & 70 & 55 & 90 & 2,5 & 42 & 1,7 & 83 & 60 & 90 & 2,7 & 50 & 1,5 \\
\hline 26 & 38 & 23 & 15 & 3,0 & 140 & 2,4 & 35 & 32 & 12 & 2,9 & 122 & 2,0 \\
\hline 29 & 45 & 34 & 54 & 2,6 & 34 & 1,3 & 55 & 14 & 45 & 2,6 & 42 & 1,3 \\
\hline 33 & 27 & 12 & 38 & 2,8 & 98 & 2,9 & 34 & 22 & 42 & 2,5 & 115 & 3,0 \\
\hline 43 & 68 & 46 & 95 & 2,2 & 67 & 2,5 & 56 & 54 & 108 & 2,4 & 85 & 2,0 \\
\hline 46 & 65 & 18 & 102 & 3,0 & 55 & 1,7 & 72 & 28 & 97 & 3,0 & 40 & 1,5 \\
\hline Média & 46 & 28,5 & 60,9 & 2,67 & 81,6 & 2,59 & 50,7 & 33,4 & 69,6 & 2,56 & 83,4 & 2,52 \\
\hline $\begin{array}{l}\text { Desvio } \\
\text { Padrão }\end{array}$ & 16,8 & 15,4 & 31,2 & 0,25 & 33,8 & 0,84 & 17,0 & 15,1 & 32,7 & 0,30 & 34,7 & 1,0 \\
\hline
\end{tabular}

Valores de referência para a espécie: ALT (até 50UL ${ }^{-1}$ ) AST (até 40UL ${ }^{-1}$ ) FA (até $70 \mathrm{UL}^{-1}$ ) albumina $\left(2,5-4,6 g d L^{-1}\right)$ Uréia $\left(\right.$ até $40 \mathrm{mgdL}^{-1}$ ) Creatinina $\left(1,5-2,0 \mathrm{mgdL}^{-1}\right)$

felinos, obtendo-se negatividade no cultivo em $100 \%$ $(n=10)$ das amostras.

\section{DISCUSSÃO}

Os resultados do presente estudo, referentes à ocorrência de infecção bacteriana nas vias urinárias inferiores de felinos, são concordantes com os de outros autores (LEES et al., 1984; BARSANTI et al., 1985; DAVIDSON \& LEES, 1991; GRIFFIN \& GREGORY, 1992). Em estudo prospectivo realizado por RECHE et al. (1998), a ocorrência de cistite bacteriana nos felinos analisados foi bem inferior a do presente trabalho ( $8 \%$ vs $24,5 \%$ ). No entanto, no trabalho realizado por RECHE JUNIOR et al. (1998), foram estudados somente gatos com DTUIF, o que difere da metodologia empregada no presente experimento, onde além de gatos com DTUI, a infecção urinária foi pesquisada também em outras condições mórbidas.

Em um estudo realizado por DAVIDSON et al. (1992), foram cultivadas 1380 amostras de urina de felinos, colhidas num período de 12 anos. Observouse que, em $25 \%$ dessas amostras houve crescimento bacteriano, o que é muito próximo do valor encontrado no presente estudo (24,5\%), apesar da grande diferença de amostragens entre os dois experimentos.

A observação de que $46 \%(n=6)$ das 13 amostras de urina com cultivo positivo, eram provenientes de gatos com IRC, não pode ser considerado um fato inusitado, uma vez que tais pacientes, normalmente perderam a capacidade de concentração urinária, tornando-se assim mais predispostos à instalação e proliferação de agentes microbianos nas vias urinárias (LEES et al., 1979; OSBORNE et al., 1979; OSBORNE et al., 1989). Portanto, tal informação é de extrema importância para o clínico, que deve sempre aventar a possibilidade de complicações como a infecção urinária em pacientes felinos com IRC.

Alguns gatos com obstrução uretral também foram utilizados no presente estudo, considerando-se que o processo de sondagem uretral a que esses animais são submetidos rotineiramente para o restabelecimento do fluxo urinário, pode facilmente induzir a uma cistite bacteriana iatrogênica. De fato, 15,5\% $(n=2)$ dos gatos com cistite bacteriana eram gatos com obstrução. Tais informações são coincidentes com a de outros estudos (LESS \& ROGERS, 1986; RECHE JUNIOR et al., 1998).

Gatos com uretrostomia perineal, normalmente se tornam mais propensos a ter infecção bacteriana das vias urinárias inferiores, isso ocorre porque a uretra desses felinos passa a ser mais curta e o meato uretral localizado muito próximo ao ânus, o que facilita a ascensão de agentes bacterianos às vias urinárias (GRIFFIN \& GREGORY, 1992). De fato, no presente trabalho $15,5 \%(\mathrm{n}=2)$ dos gatos com cistite bacteriana haviam sido submetidos a uretrostomia perineal.

Os pacientes com Diabetes mellitus tornam-se mais predispostos à infecção das vias 
urinárias por vários motivos, destacando-se a presença de grandes quantidades de glicose na urina, e a produção de urina mais diluída. Dos felinos com cistite bacteriana utilizados no presente estudo, 15,5\% $(n=2)$ eram gatos diabéticos.

Os três agentes isolados que se mostraram resistentes à orbifloxacina in vitro (Corynebacterium spp, Klebsiella spp e Escherichia coli) são geralmente sensíveis às fluoroquinolonas (ÁRKÖZY, 2001). No entanto, deve-se considerar que a resistência bacteriana às quinolonas tem aumentado, por uso indiscriminado de antimicrobianos em doses e períodos muitas vezes insuficientes (ÁRKÖZY, 2001). De fato, os três pacientes com cistite bacteriana e cujos agentes isolados mostraram-se resistentes à orbifloxacina, apresentavam infecção urinária crônica e o antibiograma demonstrou resitência desses agentes a todos os antibióticos testados in vitro.

O felino do qual foi isolado o Corynebacterium spp era um paciente com inúmeras recidivas da infecção urinária e que já havia sido submetido a cinco intervenções cirúrgicas para correção de estenoses decorrentes da uretrostomia perineal. Já o paciente no qual foi isolada a Klebsiella spp era um felino diabético com controle glicêmico inadequado, uma vez que o proprietário tinha grandes dificuldades na administração de insulina e medicamentos por via oral, tais fatos devem ter colaborado para o crescimento de um agente tão resistente. O terceiro felino, em cuja amostra de urina foi isolado Escherichia coli, estava em tratamento para IRC e também já havia sido submetido a diversos tratamentos antimicrobianos para o controle da infecção urinária.

As fluoroquinolonas devem ser usadas com cautela em pacientes com alteração na filtração renal, uma vez que sua excreção é primariamente renal e secundariamente hepática (ÁRKÖZY, 2001). No presente estudo, foram utilizados vários gatos com IRC e elevados níveis séricos de uréia e creatinina. No entanto, não houve variabilidade significativa desses valores após o uso da orbifloxacina, o que pode sugerir que o uso de tal fármaco, na dose preconizada, é seguro em pacientes com IRC. Deve-se ressaltar que esses pacientes, já estavam em tratamento há algum tempo, sendo considerados compensados, em que o maior valor de uréia observado era de $120 \mathrm{mg} \mathrm{dL}^{-1}$ e de creatinia de 2,9mg dL ${ }^{-1}$. Portanto, em gatos com IRC descompensada, ou seja, animais desidratados, anoréticos e com valores séricos de uréia e creatinina elevados, recomenda-se precaução no uso das fluoroquinolonas.

Em relação às enzimas hepáticas e a albumina, também não foram observadas alterações significativas em seus níveis após o uso da orbifloxacina. Portanto, na dose preconizada a orbifloxacina não parece ser hepatotóxica para felinos.

A inexistência de ensaios clínicos utilizando-se a orbifloxacina no tratamento de outras infecções bacterianas em felinos, a exceção das dermatológicas, tem limitado sua indicação para essa espécie pelos fabricantes do fármaco. No entanto, a orbifloxacina mostrou-se extremamente eficaz no controle da infecção urinária dos pacientes felinos utilizados no presente estudo, curando $100 \%$ dos animais com cistite bacteriana. Tal fato demonstra que a orbifloxacina, a exemplo de outras fluoroquinolonas pode ser indicada no tratamento das infecções bacterianas das vias urinárias (ÁRKÖZY, 2001)

\section{CONCLUSÕES}

Os resultados do presente trabalho permitem concluir que a orbifloxacina pode ser considerada uma opção no tratamento das cistites bacterianas em felinos, e que a dose de $2,5 \mathrm{mg} \mathrm{kg}^{-1}$ é bem tolerada, não sendo observados, segundo a metodologia empregada, sinais de nefro e/ou hepatotoxicidade.

\section{AGRADECIMENTOS}

À Schering-Plough Coopers pela doação do fármaco utilizado no presente estudo (orbifloxacina ORBAX $\left.{ }^{\circledR}\right)$.

\section{REFERÊNCIAS}

ÁRKÖZY, G.S. Quinolones: a class of antimicrobial agents. Capturado em 2001. Online. Disponível na Internet http://www.vri.cz/docs/vetmed/46-10-257.pdf.

BARSANTI, J.A. et al. Feline urologic syndrome: Further investigation into etiology. Journal of the American Animal Hospital Association, v.18, n.4, p.391-395, 1982.

BARSANTI, J.A. et al. Urinary tract infection due to indwelling bladder catheters in dogs and cats. Journal of the American Veterinary Medical Association, v.187, n.4, p.384-388, 1985.

DAVIDSON, A.P.; LEES, G.E. Diagnosis and management of urinary tract infection. In: AUGUST, J.R. (ed): Consultations in feline internal medicine. Philadelphia: Saunders, 1991. p.319-325.

DAVIDSON, A.P. et al. Urinary tract infection in cats: A retrospective study, 1977-1989. California Veterinarian, v.46, n.5, p.32-34, 1992.

GRIFFIN, D.W.; GREGORY, C.R. Prevalence of bacterial urinary tract infection after perineal urethrostomy in cats. 
Journal of the American Veterinary Medical Association, v.200, n.4, p.681-684, 1992.

KRUGER, J.M. et al. Clinical evaluation of cats with lower urinary tract disease. Journal of the American Veterinary Medical Association, v.199, n.2, p.211-216, 1991.

LEES, G.E. et al. Antibacterial properties of urine: studies of feline urine specific gravity, osmolality, and $\mathrm{pH}$. Journal of the American Animal Hospital Association, v.15, n.2, p.135-139, 1979.

LEES, G.E. et al. Results of analyses and bacterial culture of urine specimens obtained from clinically normal cats by three methods. Journal of the American Veterinary Medical Association, v.184, n.4, p.449454, 1984 .

LEES, G.E.; ROGERS, K.S. Treatment of urinary tract infections in dogs and cats. Journal of the American Veterinary Medical Association, v.189, n.6, p.648-652, 1986.
OSBORNE, C.A. et al. Urinary tract infections: normal and abnormal host defense mechanisms. Veterinary Clinics of North America: Small Animal Practice, v.9, n. 4, p.587609, 1979.

OSBORNE, C.A. et al. Feline lower urinary tract disorders. In: ETTINGER, S.J. (ed). Textbook of veterinary internal medicine: diseases of the dog and cat. 3.ed. Philadelphia: Saunders, 1989. p.2057.

RECHE JUNIOR, A. et al. Estudo clínico da doença do trato urinário inferior em gatos domésticos de São Paulo. Brazilian Journal of Veterinary Research and Animal Science, v.35, n.2, p.69-74, 1998.

SCHECHTER, R.D. The significance of bacteria in feline cystitis and urolithiasis. Journal of the American Veterinary Medical Association, v.156, n.11, p.1567-1573, 1970 .

VIEIRA, S. Introdução à bioestatística. 2.ed. Rio de Janeiro: Campus, 1991. 98p. 